suggested that the spat from the first zone should be collected and transferred to the second zone in spring and finally to the third zone in summer, and that the oysters should be collected and marketed from zone three.

Experiments in deep-water tank fishing at Mopad shows that there is an increase in size in the fish. The tank had been stocked with fingerlings of local carp, including catla, which is the quickest growing and attains a large size. Catla are probably bottom dwellers as they are only caught with the Ennur nets and cast nets which descend to the bottom. Investigations into the growth of the catla show that fish 4-9 in. long may grow to $13-17 \mathrm{in.}$ in four months and that they attain a length of $13-14 \mathrm{in}$. in a year and $23 \mathrm{in}$. in two years, weighing $6 \mathrm{lb}$. after the first year and I5 lb. after two years. 'Thus it is very suitable for rural pond culture. Several pieces of water have been stocked with these and other fish.

Part of the Report relates to various problems in marine, estuarine, and inland fisheries, including scientific and technical research, administration, pearl and chank fisheries, socio-economic work and publications: part 2 relates to finance: part 3 to the staff. Appendices deal with statistics.

\title{
The University of Edinburgh.
}

\section{Extension of Departments of Geology and Engineering.}

$\mathrm{O}^{\mathrm{N}}$ Jan. 28, the Prime Minister opened two recently completed extensions of the University of Edinburgh-the Grant Institute of Geology and the Sanderson Laboratories of Engineering-erected on the West Mains site, on the southern cdge of the city, adjacent to the Departments of Chemistry, Zoology, and Animal Genetics, all of which are post-War extensions. The new Institute of Geology has been provided by Sir Alexander Grant, who gave $£ 50,000$ for this purpose; the new Engineering Laboratories have been built from a bequest of $£ 50,000$ by $\mathrm{Mr}$. James Sanderson of Galashiels and a gift of $\$ 2000$ by the Carnegie Trust. The chancellor of the University, Sir James M. Barrie, presided at each of the opening ceremonies, and his brief introductory remarks were characterised by his usual charm and humour. Among those present at the ceremony in the Geology Department were the Lord Provost of Edinburgh, Sir Thomas Holland, the Right Hon. Sir A. Sinclair (Secretary of State for Scotland), Lord Elgin, Sir Alexander and Lady Grant, and a number of wellknown geologists, including Sir John Flett, Profs. W. W. Watts, W. T. Gordon, O. T. Jones, E. B. Bailey, and P. G. H. Boswell.

In opening the building, the Prime Minister spoke in a manner which revealed his own interest in geology and his pleasure in recalling his study of "Vestiges of Creation", and of Hugh Miller's "Footprints of the Creator" and the "Testimony of the Rocks", and of "the wonderful Saturdays spent in trying to discover in the Tynet Burn, where Hugh Miller and others worked, those nodules which split to reveal their secrets.... That extraordinarily characteristically Scottish controversy on the six days of creation has contributed more than any other controversy to stimulating the general intellectual curiosity of the generation to which I belong and of the generation immediately preceding. . . . Those who enter these walls now will perhaps not find in the study of geology such an invigorating background."

"I am not at all sure", Mr. MacDonald continued, "that scientific investigation can be adequately carried out, can receive the stimulus required for its continued progress, unless those who are experts manage somehow or other to keep in contact with the young men of the street and the market-place. In a conversation I had not long ago with Einstein, I accused him of destroying elementary science. He defended himself with the vigour you can imagine. I laid down the proposition that scientific knowledge must not be so far ahead of common interest that it becomes isolated from the ordinary intellectual life and curiosity of its generation. That is a problem for you to solve. Surely, dull must bo the human mind when it ceases to take an interest in the world, its structure, its evolution, the forces that have made it and that may in time destroy it. When we cease to take an interest in that, when we cease to feel the inspiration of that which is on the border-line of the known and the unknown, the knowable and the unknowable, then I think everything that characterises human intelligence will have gone out of it."

Prof. T. J. Jehu expressed the thanks of the University to the Prime Minister and to Sir Alexander Grant.

A similarly distinguished gathering which assembled in the Engineering Department included also repre. sentatives of the Sanderson Trustees, Sir Murdoch MacDonald, representing the Institution of Civil Engineers, and Prof. J. D. Cormack, the University of Glasgow. The Prime Minister, in opening the Department, referred to the evolution in the meaning of the term engineering-once purely a military process but now become mainly a civil process-a point which he will carry with him to Geneva. He observed how the University of Edinburgh is equipping itself for the future-a future of skill, of adaptation of the powers of scientific discovery to commercial operations upon the success of which and the international freo flow of which depend the well-being and the wealth of every individual nation on the face of the earth. "You are not going to establish", he said, "the greatness of a State or the greatness of a people on material achievements alone. The more we advance in our engineering achievements the more must we be careful of the soul and the spirit of things. Edinburgh turned into a factory only would not be the Edinburgh that inspired us all and made us proud that it is our capital city. Nor must the city be a dead museum. The ghosts of the past must never be banished from the streets of Edinburgh. But while preserving that, while planning our Edin. burgh that these ghosts are not laid by the efficient brutalities of up-to-date materialism, we must see that our Edinburgh in its institutions, in its work, above all in its University, must equip its young men and its young women with a full knowledge of the past and yet able and efficient to make future contributions to the glory and greatness of our city. Brains, knowledge, and capacity are to be put at the disposal of what I am convinced is a developing nation. In these days the development of a nation and its prosperity depend very largely on the way that it uses mechanical power. The adaptation of driving power to new forms of material, the capacity to apply scientific discovery, are the lines upon which this nation is going to move out of the past into the future. All things pass away, everything becomes new, and that text cannot be better applied to anything than to the evolution of power to transport."

Sir Thomas Hudson Beare offered to the Prime Minister and to the Sanderson Trustees the thanks of the University.

No. 3249, VoL. 129] 